\title{
Old Man River and A River Story: 'Eco-cinema' in North East India
}

\author{
BharatiBharali \\ (Assistant Professor, Department of Communication and Journalism/ Gauhati University, Assam, India)
}

\begin{abstract}
Documentary films are considered as one of the "discourses of sobriety" that include all the elements of life. Based on realities, documentary films are mirror of sorrows and sufferings of people and have the universal cultural expression.

The mighty river Brahmaputra has nourished the lives of North East India including trans-national natives in its majestic journey. Like other 'eco-cinema', many filmmakers have depicted the association between Brahmaputra and its communities from their point of view. 'Eco-cinema' represents a diversity of creative productions that addresses issues related to the intertwined relationship between human and natural world as well as retrain perception as an alternative to conventional media spectatorship. This paper attempts to understand how documentary films are engaging river Brahmaputra as a source of eco-cinema to understand the socio-cultural ethos in North East India. The Old Man River of Gautam Bora and A River story of hope and despair by MouliSenapati were taken into consideration to comprehend the norms of visual language practiced in this part of the world.

Like many rivers of the world, Brahmaputra shapes the valley with its own command. The river sometime is the source of all miseries for the valley. Man becomes helpless in front of the nature's will. Their peace, happiness and dreams shatter when the river becomes a gigantic one; only the struggle for existence remains as the background music of life. Extensive use of extreme long and close-up shots is a fascinating common character in the films that no doubt creates the emotional bonding of the audience and the narrative content.
\end{abstract}

Keywords:Documentary film, Eco-cinema, Brahmaputra, Assam, visual language

\section{Introduction}

Documentary films, in the words of the noted film scholar Bill Nichols, are one of the "discourses of sobriety" that include nature, economics, politics, and history-discourses that claim to describe the "real" to tell truth [1]. Earliest documented use of the term "documentary" (French: 'documentaire') was in the initial travelogues written in the twentieth century. In the academic context, John Grierson, a pioneering Scottish documentary filmmaker who was often considered to be the father of British and Canadian documentary film, first used the term 'documentary' while reviewing Robert Fleherty'sMoana where he argued documentary as 'the creative treatment of actuality'. This 'actuality' according to Ivor Montagu (1964) [2] is the raw material that the documentary filmmakers compose in the cinematographic record of visual aspects of reality. The reality emphasized here is often subjective in nature because a film irrespective of fiction or non-fiction is only an externalization of a director's point of view. It encompasses all the film techniques in which camera angles, distance, and movement replicate a particular character's vantage point.

A concrete definition of what a documentary film is difficult to put forward as the innumerable type of reality a documentary can portray, varied content it may consider and the way it would present subject matter has generated debate over the last few decades. Representation, reconstruction and interpretations of reality are among some of the basic controversial terminological modes that try to distinguish documentary from news and record. Whether documentary depicts 'real' object has been coherently argued by the German documentary dramatist Peter Weiss (1971)[3]. He contends that documentary theater takes authentic materials and 'puts it on the stage, unaltered in content, edited in form'. According to Weiss, documentary is the borne of negotiation between two potentially conflicting factors: the real and its representation.

Documentary is said to be the 'young genre of young art' evolving, growing and nursed by each and every director at all time. When some are worried that feature, over-dramatization and montage paralyze the beauty and originality of this creative art others are hopeful that documentary subject is authentic and has grip at the ground level, point of view is always a closer nexus between content and how content is articulated in film language and flow of story- line is non- routine and stimulating. 


\section{Significance of the Study}

The emphasis of this study is to explore nature - human relationship in the visual languages of Assam, India. The study of this kind of relationship can be cited similar to the discourse of eco-criticism- a new branch in literature where man- nature relationship has been the center of discussion.

Documentary film history shows that nature has always attracted the film makers. From Thomas Edition's experiments to Robert Flaherty, even the early filmmakers have depicted nature and man's view through their camera. Hunting as sports was the prime issue in earlier days. It was Robert Flaherty who for the first time reenacted the man's struggle with nature. Since his main theme was man's adaptability with nature, Flaherty linked to explore the essence of his surroundings against which his hero's are fighting. His films thus became both the exploration and discovery of these small details of nature. In his film Man of Aran(1934), Flaherty converted the lifeless sea into a living monster. He showed how the massive waves of the sea rose up and dwarfed men. In this way, they served as Flaherty's symbolic man against nature's will.

The famous filmmaker Pare Lorenz's the most admirable documentary 'The River' (1937) presented an urgent problem of how to use natural resources properly. He visualized in dramatic terms, man's abuse of the Mississippi River Valley in the past decades. This can be cited as a pure form of motherly attitude of a documentary film maker of nature genre since its inception. Keeping in view this relationship, the study tries to explore the trend of nature representation in the documentary films in India with special focus on Assam. There will be a subjective focus on the point of view of a filmmaker which is built on the cultural strata he belongs to and the cinematic language as an externalization of his internal aesthetics. This hence incorporates the making of nature genre documentary in Assam with a highlight on the social circumstances of the state that helped to build up encoded meanings in a film by its applauded director. Although this branch of film study is still growing, little attention has been paid in Indian circumference. The study thus shall fill this gap by examining how this prominent mode of visual culture represents nature human relation in India in general and Assam in particular.

The findings of the study are expected to suggest the art of practice performed by individual filmmakers and their accommodation of cultural approach while maintaining their expression and identity. Documentary film particularly nature films have the power to function as a cultural commentator. Therefore when examined as a cultural commentary, documentary films in nature genre shall reveal a diversity of origin and perspectives that constitute the character of people of this land and contribute to Indian consciousness. Findings will certainly convey the potential of eco-cinema and their engagement in this part of the country as well as reveals the pedagogic importance.

\section{Objectives of the Study}

The central objective of our study is to conduct an in-depth evaluation of non-fiction films as a medium for presenting the association of man and river in the documentaries produced in Assam.

The second objective of this paper is to explore how 'culturally derived codes and shared artistic codes $^{1}$ influence in the formation of specific language of the film. It will be studied with the help of narratives of the film. Narrative with its universal constructive format (written, spoken, poetry, prose, image, song, theater or dance) describes a sequence of fictional or non- fictional event. The most common narrative form that constructs relations between story, events and their narration is 'singulative'(i.e. telling once what 'happened') in nature. One of the characteristics of modern narratives is the subversive treatment of the various categories of time, elimination of which will eliminate all narrative quality.

\section{Research Questions}

Research questions are based on the objectives of the study. These are -

- Documentary films that reflect nature is important but how they reflect the concept of eco cinema?

- What point of views these documentaries present? Is there any anthromorphic bond that the films generate in the mind of audience?

\footnotetext{
${ }^{1}$ The association between cultural codes and cinematic language is a much discussed topic in film study. Christian Metz - the philosopher and film semiotician articulated that film image is the borne of cultural and mental perception. The explanation part of a film is always challenging as film as a viewing substance is to be understood without the knowledge of its language. More of his work can be understood from his much acclaimed book Film Language: A Semiotics of Cinema (1974), 1991, The University of Chicago Press. Here he states that cinema (whether fictional or non -fictional) is a vast subject, and there are more ways than one to enter it. Taken as a whole, it first of 11 a fact and as such it raise problems of aesthetic, of sociology and of semiotics as well as of the psychologies of the perception and intellection. He further states '...... as an anthropological fact, the cinema has a certain configuration, certain fixed structure and figures, which deserve to be studied directly.'
} 


\section{Methods}

The study is based on both primary and secondary data. Primary data here consists of the documentary films chosen for this study. These films represent nature and have environmental merits within the constraints of film making. Joseph Gibaldi in his book MLA Handbook for Writers of Research Papers[4] states that primary research is the study of a subject through firsthand observation and investigation, such as analyzing a literary or a historical text or a film or a performance, interview/ survey etc. Secondary data comprises of books, journals and reviews from various library and web sources. Samples in this study were restricted to the films produced in Assam and by the directors from Assam after. Our approach is purely deductive in nature.

\section{Research Design}

The approaches of visual analysis taken for consideration in this study are based on the analysis of collective images rather than single image. Much of this work is indebted to Theo Van Leeuwen and Carry Jewitt (2008) [5] whose fascinating works on visual analysis has inspired us to explore in our field. According to Van Leeuwen and Carry, visual analysis may be based on what is visible within the image or collection of images as with the content analysis and also with the various types of semiotic analysis. These images may be self-sufficient or capable of being inserted into many different contexts as like as in the study of fine arts.

According to film critic James Monaco, the image is experienced as both an optical and a mental phenomenon. This optical pattern is read saccadically: the mental experience is the result of the sum of cultural determinants and is formed by it. This mental and optical intellection combine in the concept of sign where signifier is related to signified. These signs when read in conjugation with cultural and saccadic aspects produce the meaning either denotative or a connotative one. Documentary filmmakers like the non-fiction filmmakers also prefer to modify space ("mise- en- scéne") and time (montage) for developing the relationship between sign and codes. This model of 'reading' and 'understanding' therefore carries significance for studying even nonfiction film.

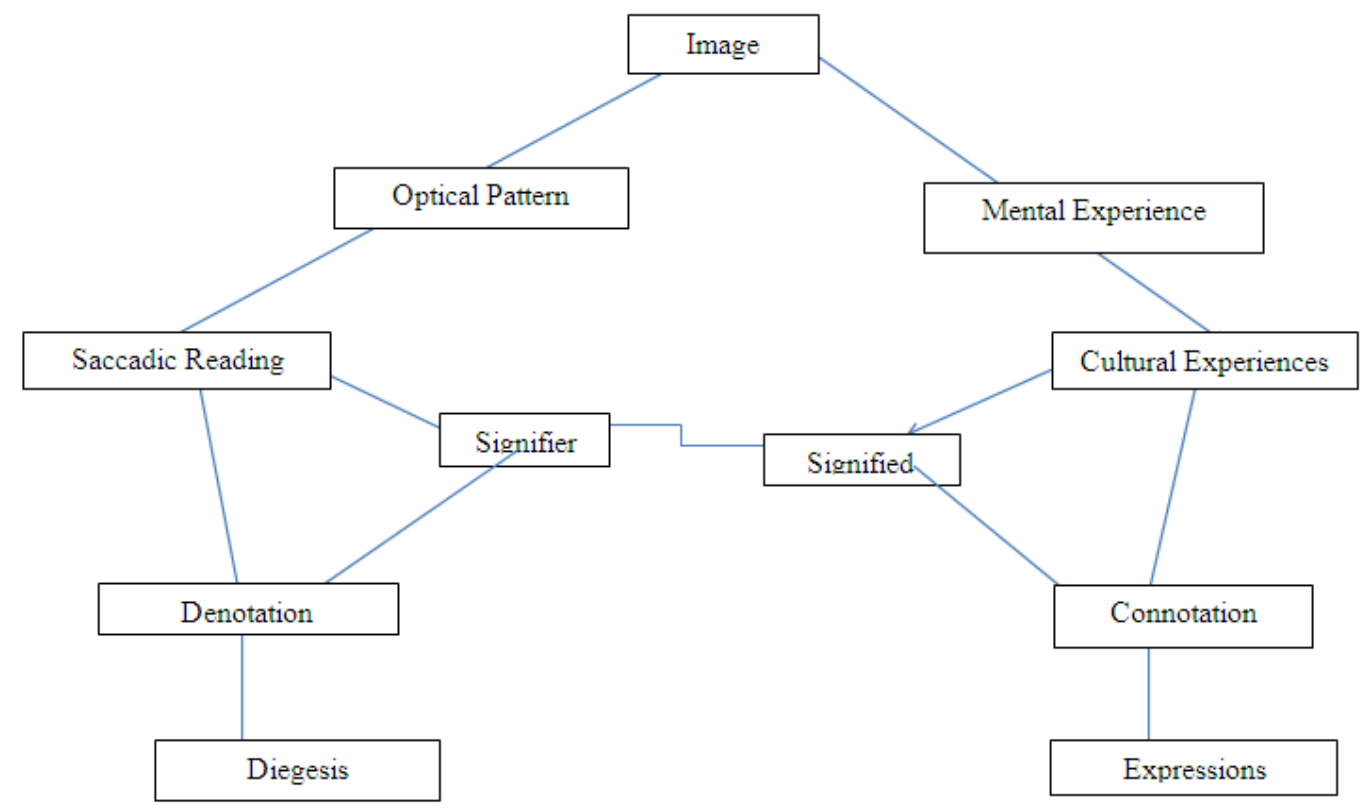

Figure 2.1: Reading the Image (Monaco, 194) [6]

\section{Documentary Film in India}

In spite of the entire differing views among film scholars in general, Lumiere brothers are considered as the pioneer of documentary films. The first film they made was Workers Leaving the Lumiere Factory (1895), a combination of continuous, un edited footage of real events showing how the workers came out of the factory . Prior to Lumiere brothers, Thomas Edition invented movie machine and experimented on photographic reality as visual records of actuality. He is also cited as the first man who first experimented to produce nature film. Footage of his film 'Feeding the Swan' (1898) is noted for its experimental use of filmic space which also serves as an initial cinematographic experiment in documentary film. After the entry of color into visual language, documentary production got a new vigor. Growth of television in mass scale and spread of cable television had enhanced the documentary film industry. Development of story line and content was of much noticeable in the 70s and 80s along with much technological inputs and experiments. 'The phenomenon of 'reality television' accelerated the pace and helped to generate a new lineage named 'feature-documentary'. The early years of twenty first century have witnessed significant development in the technology, commercial 
aspects, and aesthetics, social and political dimensions. By the late twentieth century documentary proved that it can be vitally dramatic and can become an opinion builder in a pluralistic society provided a free environment for freedom of speech and expression. Change in authorship, intrusion of cyberspace, heterogeneity in audience perspective and establishment of documentary film study as an academic branch at international schools have promulgated the expedition of non-fiction film.

The first Indian documentary in true sense was made by DhundirajGovindPhalke, popularly known as Dadasaheb. On a pea plant named, 'Growth of a Pea Plant'(Narwekar,1992) [7]. After Dadasaheb, the earliest recorded documentary in India is that of Mohan Bhavnani. He made two realer short story named Mysore- Gem City of India in 1929. By the end of the 1930s, the short film movement had gained considerable ground in the country although they were in the newsreel format. The Second World War had instigated the growth of nonfiction film production. This was obviously to boost the war effort towards British reign Establishment of Films Division boosted the filmmaking industry of India.

Although television came to India in 1950s, it was merely after the 1980s that television became the major source of entertainment. This on the other side also influenced the documentary film productions under the banner of commissioned programmes. Set up of film institutions and organizations like IDPA (Independent Documentary Film Producers in India) are in favor of a fertile ground for the development of non- fiction films culture in the in present time as well as its boom in near future. Establishment and growth of film festivals in the country like MIIF (Mumbai International Film for Documentary, Short and Animation Films), CMS Vatavaran (Environment and Wildlife Film Festival) and others also promoted the journey of documentary film making in this country.

\section{Concept of 'Eco- cinema'}

History of film making reveals that the first images displayed by Muybridge with his Zoospraxiscope device in 1872 were of a galloping horse in motion. Soon after this he experimented various animals in motion and published it in 1887. Thomas Edition during this time experimented on animals which we can consider as the forerunners of documentary films on natural animals. During the first decade of the twentieth century (19001909),earliest examples of films came into existence which falls under one or another of the nature genres various format. Editions portray of Yellowstone National Park through Riverside Geyser, Yellowstone Park and Upper Falls of the Yellowstone (1901) set the trend of travelogue under nature genre which is followed by almost all the modern nature based channels including Discovery, National Geographic along with BBC and rest of the leading media organizations today. In 1922, the documentary in many ways was legitimized. Robert Flaherty, the 'Wordsworth of Documentary film' released his famous Nanook of the North where scenes of wild animals and human journey of struggle for adaptation with its environment was the central theme of attraction. Flaherty's way of presentation had given new dimension to the nature genre in particular and documentary film making process as a whole. Soon after the end of World War II, Walt Disney inaugurated a hugely successful series of 'true life adventure' in which nature in the continental United States was depicted. A lot many documentaries appeared in this period which extensively focused on the man- nature relationship as well as the place of human being within nature thus enhancing the ideology of system theory which sees our world as a system- a part of the larger world system.

The production of nature related documentaries had expanded geometrically with the establishment of a number of popular channels like National Geographic, Discovery and, Animal Planet etc. since late eighties. With its insatiable demand for content, these films have become more popular and even more numerous making the documentaries a source of 'infotainment'.

In popular parlance, the wildlife film has come to represent the nature film. According to Gregg Mitman (2009), [8] nature films seek to "reproduce the aesthetic qualities of pristine wilderness and to preserve the wildlife that is fast vanishing from the face of earth". Derek Bousé, in Wildlife films[9]recognizes seven primary characteristics of nature films: 1) the depiction of mega fauna; 2) Visual splendor; 3) dramatic story line; 4) absence of science; 5) absence of politics; 6) absence of historical reference points and 7) absence of people.

Salma BasantiMonani (2008) [10] while working on Nature films and the challenge of just sustainability had argued three possible types of nature documentary films considering the representation of nature and socio political or human relations. According to her, if there is only 1) depiction of mega and no scientific objectivity then this can be termed as wildlife- nature films. This type of films is free from political influence on wildlife. Human characters are never presented instead animals are anthropomorphized. March of the Penguin (2005)[11]falls under this category. 2) If nature is depicted as wild, science becomes Darwinian terms of 'survival of the fittest' and human existence is intensely individualizes and depicted as noble or brutal savage, then this can be categorized as Adventure- Nature films. Steve and Terri Irwin's much debated show Crocodile Hunter (1992) on Animal Planet is a good example of this type of documentary 3) When nature and humans are intrinsically intertwined and portrayed as being innovatively adapted, where nature is considered as 
the life supporting resource than these films become social-nature films. In this category, politics is considered in the context of socio-economic institutions. Historical perspective of nature human relationship is another characteristic of social nature documentaries. Scientific objectivity here becomes a quest for knowledge of human individuals. Diana and Leanne Wilson's 2004 documentary Being Caribou is a beautiful example in this category although there are plenty.

The term 'eco-cinema' was first coined by Scott Macdonald in his article Towards Eco cinema[12] in the journal Interdisciplinary Studies in Literature and Environment (ISLE). Here Macdonald focuses on the retraining of the perception of the audience gaze that further influence the association between human and nature. He states that such 'nature' films 'provides an evocation of the experience of being immersed in the natural world' (108) that is an alternative to conventional media spectatorship. Paula WilloqouetMaricondi,[13] a film critic further elaborate this definition of eco cinema and states that eco-cinema has the potential to raise awareness about contemporary environmental threats and, in some instances even intervene in an issue and precipitate concrete changes through the very process of film making. Further, she says,

I will define eco-cinema as encompassing documentary, fiction, and experimental films that seriously address issues of ecological import, foster environmental awareness, protection and conservation, and that in a broader sense encourage us to reflect on what it means to be a part of natural environment, to belong to the biotic community that includes humans. (p.127)

These definitions lead us to undertake the works of two most acclaimed directors Gautam Bora and MouleeSenapati for understanding the mode of their representation of the association of the people with the river of the state.

\section{Old Man Riverand A River Story: 'Eco-cinema' in the Brahmaputra Valley}

The river Brahmputra is considered as the lifeline of the people of Assam. This mighty river is one of the greatest rivers of the world in terms of the volume of the water it carries, amount of sediments it takes alongside and the vitality of civilization that grew up on its valley[14]. Encompassing three countries in its majestic journey, Brahmaputra with its different names in different places has fertile the lands of Tibet, India and Bangladesh. Many colourful ethnic groups and cultures has been nourished by the river Brahmaputra through its long 3000 k.m. (approx.) of voyage from Himalaya to the Bay of Bengal. The contribution of river Brahmaputra was admired by many artists, literates and film makers from time immemorial. Assamese literature is flooded with such association of the river and the native people. It was Sanjay Hazarika- a leading producer of the state as well as a social activist is credited to depict this bonding in visual language through his series of documentary for Doordarshan -a public service broadcaster in India. Uttering the role of Brahmaputra in this society, he once said, the river is revered in legend, ballads and contemporary literature as the most visible face of Assam and the North-east, dominating the geography, history and cultures of both Arunachal Pradesh and Assam.

Old Man River (Dir. Gautam Bora, durations: 53:10) and A River Storyof Hope and Despair (Dir. MouleenathSenapati, dur. 53:23) tell about the tales of Brahmaputra and people living under its shadow. In both the films, the mighty river becomes a gigantic one during monsoon and devastating flood occurs leaving no room for the helpless people. Both the documentaries show the eye level shots of swelling Brahmaputra, so that, audience feels the boundless horizon of the mighty river and can be lost in the strong waves like any other villagers of the flood effected Assam.

In Old Man River, Gautam Boratakes a central character from Mishing community of Assam, and narrates the story from his point of view. It's, as if an autobiography of the Mishing man where the pages of the old man is written with each and every sands of Brahmaputra. Through the old man, the director speaks about the second largest tribal community of Assam. This is not the first instance that Mr. Bora talks about the Mishing. Instead, his earlier documentary film Mishing- the sons of Abotani was the visual anthology of the community. Old Man River differs from this in both treatment and type of storytelling. When Mishing- the sons of Abatoni speaks in an expository style, the old man river is a combination of poetic, expository and explanation type of documentary. Here, the director plays with eye level extreme long shots of Brahmaputra and its shore, to raise the richness and massive character of the river.

The film shows us more than what the strong river does in the life of the people. It is a triangular shared bonding among the community, their livestock and the river. The sheer dedication and affection of the old man and his off springs towards their domestic buffalo's one of the major significance of the film. The family which is ruined by the floods of Brahmaputra lives no stone unturned for the sustainability of the animals. The family takes the buffalos to high grass land, sometimes long away from home during flood to meet their hunger. If the animals cannot swim, they pick them up to the boat and nourish them like own child if and when required. A tension occurs among the family members who remains at the land and observe the swim of both men and the animals (Fig 1). Here director Bora is successful in portraying a human-nature bonding in a 
flood affected area where people had the highest scope for being selfish and live the animals in distress. Even in this turmoil, the old man maintains his respect towards Brahmaputra and worship the river as God. His age old faith remains intake in that 'Baba (God- the male river Brahmaputra) can never do anything wrong'.

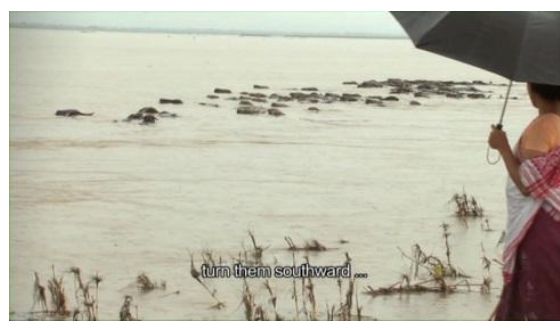

Fig 1: The women become anxious of her family members - her brothers and the buffalos

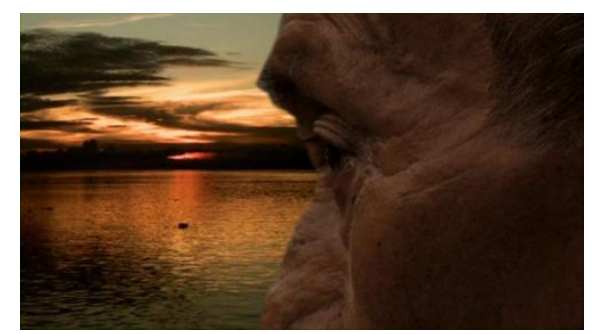

Fig 2:The old man and his river

Skilled treatment and cinematography of the Old man River reminds us the most applauded documentary film of Robert Flaherty's Nanook of the North (1922 ) [15]. The struggle of Nanook and his family in far Antarctica is not a separated one in this distant area of north east India, where an old man and his family, including the buffalos go for struggle for existence against the odd waves of Brahmputra even in this century. Only the presence of mobile phone remains as a signifier of time in this film and reminds us that Old man River is made in the twenty first century. But unlike Nanook, the director does not let us know if this painstaking effort of the old man against nature is true for all members of his community or it is only he who for the sake of his animals does this brave act. The narrative and the story telling of the film have been beautifully supported by the music of the film. The skilled adjustment of natural sound of the river reminds us that the vastness and power of the swelling nature during monsoon. The modification of time and space has been portrayed by the filmmaker with the help of the canvas-like long shots of the river.

A River Story, on the other hand, is a collection of sorrows and sufferings of the people on the bank of the river Brahmaputra. It reflects the bitter truths of man-made embankments alongside the river. The director moves on from the north bank of the river -from Matmora, Dhemaji District of Assam to the west bank -till Palasbari of Kamrup rural where flood affected people open up their miseries in front of camera. In an interview style, the director narrates himself the story of hopes and desires of the riverine folk. Senapati not only gives the first layer of direct effect of flood but also give the threatened business, changing lifestyle and psychology of a society which needs to shift from one place to another for survival. A lady describes how this society has been facing the challenges of changing mind set particularly in lacking interest on education, good governance and developmental issue. These people are forced to think only for survival during and after the natural calamity. What the Government support is going on are either not reachable at many pockets of the flood effected areas or are insufficient for them. These people, instead of some temporary solutions, demands for permanent one for the situation. The documentary, in other sense, asks the audience for rethinking on the policies of government in purview of the sufferings of these people. Long shots of the river when shows the power of nature, at the same time, justifiable amount of close up and mid close up shots presents the helplessness of man in front of the nature.

Here, nature is the supreme one. For a passed out student of Film and Television Institute of India, Pune, preparation of cinematic language with montage is not a challenging task. Senapati, choose a small boy with his toy car. The boy while walking takes the car which is bound to a rope not identical to the car. The toy car moves on a muddy road, thus reflecting the situation of the vehicles that runs along the area (Fig 1).

As James Monaco states, the audience get apsychological experiences of the ill fate of these people by this montage where the denotative meaning comes from the viewer's experience with the natural calamity. This montage is strong enough to depict the future of the boy that is revealed in the next few shots where the director shows how good farmers turn into 'bad boys' who chase for money by helping drivers in carrying out of their cars from muds created by the flood. (Fig2). Thus the boy and his toy car becomes the signifier for what was signified in the later shots. A River Storyis an epitaph of year long trial of domination of man over nature and 
the extent people have to pay for that. Yet, the documentary with a beautiful montage of a wheel of a rickshaw fading on the waves of Brahmaputra at end, says about the mobility of life that goes on, the bonding these people still keeps on for the river in their heart. In this montage shot, the director reflects the vastness of the river Brahmaputra and seems to reflect that the people who live by the river side are always in the heart of the river. Those who never go away are taken up by the river. This shows MauleeSenapati's portrayal of nature as a gigantic force against man.

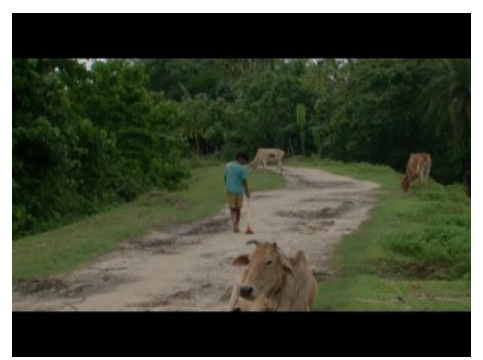

Fig 3: Montage of a boy and his toy car revealing the pathetic conditions of the people

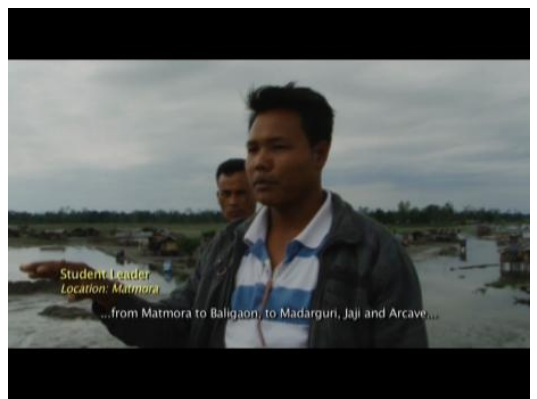

Fig 4: A flood effected student of Matmora talks about their conditions

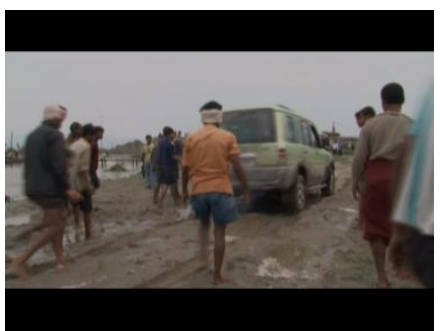

Fig: 5 the good farmers' turns into 'bad boys' by the river

This film basically centers on the interviews of the affected persons. The journey of the camera here is the journey of the director. Whatever reveals is the perception and viewpoint of the director only. As we have seen, in the first scene the director moves on a rickshaw and narrates the story of the rickshaw puller in first person. Although dissimilar in the content, the style of presentation of MauleeSenapati seems to be similar with the film named Homeland: Four Portraits of Native Action (Dir. Roberta Grossman, 2005)[16] where four persons of the four communities who are 'environmental defenders' talks about their sorrows and sufferings in front of the camera. But unlike Homeland, A river story does not end with positive outcome, instead, it left the audience to think how these people is bound to live with the un friendly tune of the nature and how the repeated efforts of the government is a failure in every year. This depicts the helplessness of men in front of the nature's will.

\section{Conclusions}

Old man River and A River Story are no doubt social issue documentaries. These type of documentaries as classified by Bill Nichols [17] primarily speaks of public issues from a social perspective where style of production is secondary to the content of the film. These films have a problem-solution structure to the narratives that account for aspects of the historic world by means of their representation. Scientific objectivity and importance of history are other chief tenets of this genre. Social-nature documentaries; a sub category of social issue documentaries where the intertwined relationship of man and nature is a prime objective as suggested by Monani. Like other eco-cinema the focus and thematic pattern of content of such films always revolves around adaptability of human and nature. The emotional binding shared by human towards nature is 
often a recurrent theme in these documentaries. Many of the films in this category also portray the effect of evolutionary history in the change of behavioral pattern of natural beings.

The narrative structure of storytelling in Old man River and A River Storyshows that the filmmakers are interested in visualizing the myriad solutions for survival that the river has brought forth (a characteristic of the social nature documentary films). In other words, it is a subjective experience whereby the narrator directly narrates all the difficulties involved in the riverine life, rather than leaving that task to audience (Horak, 2006) [18]. The films use 'micro-questions' in film narratives- that are answered by an event or scene that follows almost immediately, rather than 'macro-questions' which is answered in long, complex and overarching narratives.

Nature is inseparable from the culture of man. Natives in this part of India consider nature as 'God' even though they are dwarfed by the power of nature. Both Old man River and A River Storyreflects this ideology through their central characters and present the anthropomorphic bonding that exists throughout the culture and individuals. Old man River and A River Storytherefore can be considered aseco-cinema which is an alternative to conventional media spectatorship. As like MacDonald stated in the definitions of eco cinema, these two films are also capable of retraining the perception of the audience gaze and influence the river to think of the human-nature relationship that exist in the Brahmaputra Valley of Assam.

\section{References}

[1]. Godmilow, J and A. L Sharpio. How real is the Reality in DocumentaryFilm. History and Theory, 36 (4) 1997, 80-101.

[2]. Montagu, I. Film World. Baltimore: Penguine Books, 1964.

[3]. Weiss, P. "The Material and Models: notes towards a definition of documentary Theatre." Theatre Quaterly, (1) (1971): 41-5

[4]. Gibaldi, J. MLA Handbook for writers of Research Papers (New Delhi: Affiliated East-West Press PVT Ltd, 2003)

[5]. Van Leeuwen, Theo and Jewitt Carry. Handbook of Visual Analysis( London: Sage, 2008 ).

[6]. Monaco, James. How to Read a Film (1977, 4th ed. New York: Oxford University Press, 2009).

[7]. Narweker, S. Film Division and the Indian Documentary (New Delhi: Publication Division, Ministry of Information and Broadcasting, Government of India, 1992).

[8]. Mitman, G. Reel Nature; America's Romance with Wild Life on Film (Cambridge: Havard University Press, 1999).

[9]. Bouse, Derek. Wildlife Films (Pheladelphia: University of Pensylvania Press. 2000).

[10]. Monani, S. B. Nature Films and the Challenge of Just Sustainability. Minnesota: An Unpublisheddoctoral Dissertation submitted to the University of Minnesota, 2008.

[11]. March of the Penguins, Dir. Luc Jacquet, Warner Independent Pictures and National Geographic Feature Films, 2005.

[12]. Macdonald, Scott. Toward an Eco-Cinema Interdisciplinary Studies in Literature and Environment, 11.2 (Summer 2004): 108-132

[13]. Willoquet Maricondi, P (ed). Framing the World: Explorers in Ecocriticism and Film (Charlottevesville and london: University of Virginia Press, 2010).

[14]. Nanook of the North, Dir. Robert Flaherty . 1922. DVD. Criterion Collection, 1998.

[15]. Hazarika, S. The Brahmaputra: muse, metaphor, source of life. India International Centre Quarterly (2005). Vol. 32, No. 2/3, 243252

[16]. Homeland: Four Portraits of Native Action. Dir. Roberta Grossman. Katahdin Foundation, 2005.

[17]. Nichols, B. Introduction to Documentary. Bloomington and Indianapolis: Indianna University Press, 2001. English.

[18]. Horak, J. C. "Wildlife Documentaries: From Classical Forms to Reality TV." Film Theory (2006): 459-475. 